3. Воборил Л. Функционирование графики и лексики в компьютерной форме речи // Русский язык: исторические судьбы и современность: III Междунар. конгресс исследователей русского языка. М., 2007. - С. 405-409.

4. Выгонский С. И. Обратная сторона Интернета - Р. н/Д: Феникс, 2010. - 124 с.

5. Гончаренко А. К. Вопросы теории поликодового текста // Вестник ТГУ. Сер. филологии. - 2011. № 2. - С. 233-240.

6. Палкова А. В. Лингвистические особенности SMS-коммуникации (на материале немецкого языка) [Электронный ресурс]. - Режим доступа: http://www.rgf.tversu.ru.

7. Сон Л. П. Лексико-семантические особенности интернет-коммуникации // Вестник Пятигорского государственного лингвистического университета. - 2009. - № 1. - С. 194-197.

8. Федотченко Ю. В социальных сетях Twitter - 140 символов самовыражения - Питер. - 2011. - 144 c.

\title{
Байдашева Э.М.
}

\section{Значение английских прилагательных цвета в языке медицины}

ФГБОУ ВО Астраханский ГМУ Минздрава России Астраханский государственный медицинский университет (Россия, Астрахань)

doi: $10.18411 / \mathrm{lj}-10-2019-213$

idsp: ljournal-10-2019-213

\section{Аннотация}

Статья посвящена формированию состава группы прилагательных цвета в языке медицины. Выявлено, что несколько критериев позволяет отнести то или иное прилагательное цвета к основным - это частота употребления, отсутствие или наличие внутренней формы, односоставность или сложный характер корня, стилистическая характеристика, сочетаемость слова в контексте.

Представленные оттенки цвета в английском языке могут образовываться добавлением к основному цвету цвета предметов, имеющих характерную окраску. Установлены, что самыми частотными являются 11 прилагательных: white, black, red, brown, green, blue, yellow, orange, rose, grey, purple. Выявлено, что в английском языке для цвета может существовать одно единственное слово для необходимого цвета.

Ключевые слова: цвет, цветообозначение, модификатор, языковые обозначения, национальные различия, оттенки цвета, частотность употребления.

\section{Abstract}

The article is devoted to the formation of the group of adjectives of color in the language of medicine. It is revealed that several criteria allow us to attribute a particular adjective of color to the main ones - it is the frequency of use, the absence or presence of an internal form, the singleness or complex nature of the root, the stylistic characteristic, the compatibility of the word in the context. Presented shades of color in English can be formed by adding to the main color of the color of objects that have a characteristic color. It is established that the most frequent are 11 adjectives: white, black, red, brown, green, blue, yellow, orange, rose, grey, purple. It is revealed that in English for a color there can be one single word for the required color.

Keywords: color, color designation, modifier, language designations, national differences, shades of color, frequency of use.

\section{Введение}

У каждого народа с древнейших времен цвет являлся одним из средств осмысления мира. Обратимся к популярному примеру национального различия в английском. Слова colour британское написание во всех англоговорящих странах и color - американское написание обозначают одно и то же значение. На русский язык оба эти слова переводятся словом «цвет», плюс они имеют дополнительные 
лексические значения, которые совпадают для обоих вариантов произношения, одинаково читаются, несмотря на различное написание самого слова. Из этого следует, что в разговорной речи различий между ними нет, а вот на письме отличия есть. Аналогичный пример, слов coloured и colored переводятся оба эти слова «окрашенный, цветной», оба читаются одинаково, несмотря на различное написание самого слова.

С точки зрения лингвистики интересным является то, что у различных народов перечень языковых обозначений основных цветов и их оттенков зачастую не совпадает: там, где русский язык заставляет своих носителей видеть два цвета: синий и голубой, англоязычные люди видят один: blue, зато нашему прилагательному «розовый» соответствуют два английских прилагательных- pink и rosy. В 1969г. антрополог Б.Берлин и лингвист П. Кей в своей книге «Основные цветовые термины» высказали идею базовых цветов и универсалий в эволюции слов цветообразования. В экспериментах, проведенных по всему миру, Берлин и Кей демонстрировали представителям разных языковых групп цвета, имеющие языковые обозначения в английском языке, и обнаружили, что не во всех языках присутствуют эти 11 терминов (красный, желтый, зеленый, синий, коричневый, фиолетовый, розовый, оранжевый, чернылй, бельй и серый).

В научной литературе рассматривались такие вопросы, как этимология и история цветовой лексики (Бахилина 1975, Василевич 2007 и др), уровень развития цветовых представлений в культурах народов мира на разных исторических этапах (Berlin B. \& Kay P. 1969 и др.); цветообозначения в составе устойчивых сочетаний ( Кайбияйнен 1995); цветообозначения в составе фразеологизмов (Бедоидзе 1997), словообразование лексики со значением цвета (Иваровская 1998; Краснянский 2001 и др.). Многие работы посвящены анализу отдельных цветообозначений (Василевич 2005 и др.). Значительные результаты достигнуты в изучении лексики со значением цвета в области психолингвистики (Фрумкина 2001, Василевич 2003 и др.). Создан «Каталог названий цвета в русском языке» и описаны современные тенденции развития словцветонаименований в русском

\section{Формирование состава группы прилагательных цвета в языке медицины}

Формирование состава группы прилагательных цвета началось со времен миграции первых племен, которых содержал слово индоевропейских корней (coвp. red) и германских (совp. green, blue, white). С тех пор и по настоящее время состав прилагательных может пополняться и изменяться: по данным исследования, проведенного А.П.Василевич, было зафиксировано более 3,5 тысяч прилагательных цвета, однако в состав активного словаря вошло только 254 слова. Из этих 254 цветообозначений самыми частотными являются 11 прилагательных: white, black, red, brown, green, blue, yellow, orange, rose, grey, purple. На долю этих слов приходится около 70 всех случаев употребления в тексте.

Согласно мнению В.А. Московича, можно выделить несколько критериев, которые позволяет отнести то или иное прилагательное цвета к основным:

1. частота употребления;

2. отсутствие или наличие внутренней формы;

3. односоставность или сложный характер корня;

4. стилистическая характеристика;

5. сочетаемость слова в контексте.

Статистический критерий является, по мнению автора, определяющим. На основании этого критерия английские прилагательные yellow, green, blue, red можно отнести к основным в первую очередь, так как эти 4 цветообозначения входят в список 850 слов «Basic English». Частотность остальных рассматриваемых прилагательных (исключаются цвета ахроматической оси -white, black, grey; «выпавшие из поля исследования хроматоним» (от греч. chroma «цвет» + onym «имя») [7, с.36]) низкая, поэтому В.Л.Москвич относит их к подосновным. В состав прилагательных цвета 
английского языка входят цветообозначения, образующиеся с помощью слов модификаторов. В английском языке используются следующие модификаторы: pale, bright, dark, light, deep, shocking, vivid, moderate, pastel, soft, dull, dirty, mat, virulent. Именно модификаторы, по мнению А.П. Василевич, являются единицами активного словаря, а не сочетания с ними (dark red, pale green, pale blue). На сочетание «модификатор + цветообозначение » действуют два фактора: во-первых, некоторые модификаторы имеют узкую сочетаемость. Например, shocking сочетается только с pink; virulent -- только с red. (cp. pус. водянисто - и прозрачно -, которые выступают в сочетаниях только с голубой; или ядовито -, который сочетается только с зеленым и, реже - с желтыл ). Во-вторых, модификаторы в 90\% случаев сочетаются со словом, входящим в группу «основных». Половина англоязычных произнося blue, имеют в виду голубой цъвет, а другая половина подразумевает синий цвет. Dark blue так скажет о синем цвете человек, который под bluе понимает голубой. Соответственно, тот, кто под понимает blue синий, о голубом цвете скажет light-blue.

В англо - русском медицинском словаре Мултановского М.П. и Иванова А.Я. из многочисленных эпонимов, терминов начинающихся с собственного имени (названий болезней, симптомов, признаков, анатомических образований, диагностических и лечебных приемов, инструментов и т.п.), в словарь включены только наиболее употребительные прилагательные и существительные с цветообозначением, «остальные описательные выражения могут быть использованы как синонимичные во избежание тавтологии» [1, с.36]. Например, с помощью некоторых суффиксов образуются новые прилагательные медицинских терминов или словосочетания: alba -. бельй, белое вещество головного мозга, blие bоу - ребенок с врожденным пороком сердиа, blue circle - синие круги, bluе cross - синий крест (чихательный газ), bluе devils - белая горячка, бред алкоголика, blue funk - боязнь смерти (у больного перед операцией), bluе pus - синий гной (при инфекиии синей палочкой). Оттенки цвета в английском языке могут образовываться добавлением к основному цвету цвета предметов, имеющих характерную окраску: albaras - кожная болезнь, белая арабская проказа, bluе deasease - синюха, ичианоз, лихорадка Скалистых гор, blue blindness слепота на синий извет, blue fever - синяя лихорадка. Кроме того, в английском языке для цвета может существовать одно единственное слово для необходимого цвета прилагательное. Например: albicant - белеющий, albinismalbinoid - белковидный, белок albinous - белковой, белковинный, альбуминовый и т.д.

Таким образом, если точно не известно написание цвета, тогда можно воспользоваться суффиксом -ish. Суффикс -ish с прилагательными служит для обозначения слабой степени качества (соответствует русскому -овати -евати). Например: bluish - синеватый, синюшный, цианотичный, bluishness - синюшность, синеватая окраска (кожи, лица, конечностей).

\section{Заключение}

Окружающий нас мир всегда окрашен тем или иным способом и естественно, что возникает необходимость применить термины цветообозначения. В английском языке используются следующие модификаторы, которые, являются единицами активного словаря, имеющие два фактора сочетаемости: узкую сочетаемость и модификаторы в 90\% случаев, которые сочетаются со словом, входящим в группу «основных» прилагательных в английском языке. Оттенки цвета в английском языке могут образовываться добавлением к основному цвету цвета предметов, имеющих характерную окраску. Из вышесказанного следует, что здоровье и состояние человека порой часто зависит от выбранного цвета настроения, эмоции, отношений и т.д.

$$
* * *
$$

1. Байдашева Э.М. Лексико - семантическое поле «цвет» в языке медицины // Вестник Астраханского государственного университета. / Гуманитарные исследования. Астрахань. - 2019. - №2 (70) - C.21- 27 
2. Бахилина Н. Б. История цветообозначений в русском языке. / Отв. ред. В.П. Филин. - М., 1975. $288 \mathrm{c}$.

3. Берлин Б., Кей П. Основные цвета.// Их универсальность и видоизменения. 1969.

4. Бедоидзе Л.Г. Фразеологические единицы с компонентом цвета в немецком, русском и осетинском Василевич А.П. Исследования лексики в психолингвистическом аспекте на материале цветообозначений в языках разных систем / Отв. ред. В.Н. Телия. Василевич А.П. - М.Наука. 1987. $-243 \mathrm{c}$.

5. Брагина А.А. «Цветовые» определения и формирование новых значений слов и словосочетаний // Лексикология и лексикография / Сборник статей под ред. С.Г. Бархударова и др. - М., 1972. - С. 73-104.

6. Иваровская В.И. Лексическое значение цветовых прилагательных в синтагматикопарадигматичесоком и словообразовательном аспектах // Вестник Санкт-Петербургского университета. Сер. 2. История, языкознание, литературоведение. 1998. - Вып. 2. - С. 104-109.

7. Кайбияйнен А.А. Устойчивые атрибутивно-субстанстивные сочетания с прилагательными цвета в современном русском языке: Автореф. ... канд. филол. наук. Казань, 1995. -19 с.

8. Краснянский В.В. Сложные цветообозначения русской речи // Традиционное и новое в русской грамматике: Сб. ст. памяти Веры Арсеньевны Белошапковой. -М., 2001. - С. 119-130.

9. Маджаева С.И. Актуальные проблемы современного терминоведения / Вестник Калмыцкого университета. 2017. - С.83-91

10. Москович В.А. 1969. Система цветообозначений в английском языке. В кн.: Вопр. языкознания. 6 : 83-87.

11. Фрумкина Р.М. Психолингвистические аспекты изучения цвета. / Фрумкина Р.М.- Москва, Наука, 1984. - C. 232.

12. Мультановский М. П., Иванова А. 1958. Англо-русский медицинский словарь. М., 635

\author{
Батова O.C. \\ Тема детства в рассказе Л. Пантелеева «Портрет» \\ ФГБОУ ВО «Волгоградский государственный технический университет»
} (Россия, Волгоград)

doi: $10.18411 / \mathrm{lj}-10-2019-214$

idsp: ljournal-10-2019-214

\title{
Аннотация
}

В статье рассматривается тема детства в рассказе Л. Пантелеева «Портрет» в свете фольклорно-мифологической традиции.

Ключевые слова: детство, пространство, мифопоэтика, фольклор, архетип

\footnotetext{
Abstract

The article deals with the theme of childhood in L. Panteleev's story "Portrait" in the light of folklore and mythological tradition.

Keywords: childhood, space, poetics, folklore, archetype
}

Активное изучение мифологического пратекста русской литературы началось, как замечает Э.Ф. Шафранская, еще в 80 -е годы XX в. Это красноречиво говорит о том, что «словесное творчество мифологично изначально, даже без осознанно постулированного писателем обращения к мифу или фольклору» [8, с. 4]. Целый ряд исследователей (А.Ю. Исаковская Х.М. Квак и др.) отмечает воплощение в произведениях отечественной и зарубежной литературы архетипической схемы волшебной сказки на уровне сюжета, образов и мотивов $[1,2]$.

Подобную реализацию схемы волшебной сказки мы встречаем и в рассказе Л. Пантелеева «Портрет». Следует подчеркнуть, рассматривая это произведение, советские литературоведы и критики в соответствии с общепринятой идеологической установкой уделяли внимание тематике и проблематике рассказа, делая акцент на его воспитательном воздействии, однако не изучали вопросы поэтики или освещали их односторонне. Поэтому анализ мифопоэтической составляющей рассказа писателя 